\title{
ERRATUM
}

Trish Keaton - Sylvia M. Dominguez $\cdot$ Ali H. Sayed

\section{Browsing the environment with the SNAP\&TELL wearable computer system}

Published online: 1 July 2005

(C) Springer-Verlag London Limited 2005

\section{Pers Ubiquit Comput (2005) D0I s00779-004-0316-5}

The extended delay in this article being published was due to a production error on the part of the publisher.

The online version of the original article can be found at http:// dx.doi.org/10.1007/s00779-004-0316-5

T. Keaton $(\square)$

Information Sciences Laboratory,

HRL Laboratories, LLC, 3011 Malibu Canyon Road,

Malibu, CA 90265, USA

E-mail: keaton@vision.caltech.edu

Tel.: + 1-818-674-2277

S. M. Dominguez $\cdot$ A. H. Sayed

Electrical Engineering Department,

University of California Los Angeles,

Los Angeles, CA 90095, USA

E-mail: sylvia@ee.ucla.edu

Tel.: + 1-818-3994560

E-mail: sayed@ee.ucla.edu

Tel.: + 1-310-2672142 